Article

\title{
Pharmaceutical Equivalence of Clarithromycin Oral Dosage Forms Marketed in Nairobi County, Kenya
}

\author{
Rebecca O. Manani ${ }^{1,2, *}$, Kennedy O. Abuga ${ }^{1}$ and Hezekiah K. Chepkwony ${ }^{2}$ \\ 1 Department of Pharmaceutical Chemistry, School of Pharmacy, University of Nairobi, P.O. Box 19676, \\ Nairobi 00202, Kenya; koabuga@uonbi.ac.ke \\ 2 National Quality Control Laboratory, P.O. Box 29726, Nairobi 00202, Kenya; kcheph@yahoo.com \\ * Correspondence: rebeccamanani@students.uonbi.ac.ke; Tel.: +254-721-540-467
}

Academic Editor: Gernot Eller

Received: 19 March 2017; Accepted: 19 April 2017; Published: 25 April 2017

\begin{abstract}
Clarithromycin is a broad-spectrum semi-synthetic macrolide indicated for treatment of pneumonias, Helicobacter pylori, and chlamydial and skin infections. The object of this study was to evaluate the pharmaceutical equivalence of 14 generic clarithromycin products marketed in Nairobi County, Kenya, to the innovator products, using in vitro dissolution profiles and similarity factors $\left(\mathrm{f}_{2}\right)$. Further, dissolution profiles of four innovator formulations manufactured in different sites were compared. Fourteen clarithromycin tablets/capsules and four suspensions were subjected to assay and comparative dissolution runs at $\mathrm{pH}$ 1.2, 4.5 and 6.8, for 60 and $90 \mathrm{~min}$, respectively. All products complied with pharmacopoeial assay specifications. However, significant differences were observed in their dissolution profiles. The non-compliance rates for tablets/capsules were $50 \%$ at $\mathrm{pH} 1.2,33 \%$ at $\mathrm{pH} 4.5$ and $50 \%$ at $\mathrm{pH} 6.8$, while none of the four suspensions were compliant. Overall, only four $(25 \%)$ products complied with the specifications for similarity factor. The results obtained indicate that a significant percentage of generic clarithromycin products are pharmaceutically non-equivalent to the innovator products, and that assay and single-point dissolution tests are insufficient demonstration of equivalence between the generic and innovator products.
\end{abstract}

Keywords: clarithromycin; comparative dissolution; similarity factor; pharmaceutical equivalence; quality

\section{Introduction}

Clarithromycin is a broad-spectrum semi-synthetic derivative of erythromycin with activity against a wide range of Gram-positive and Gram-negative bacteria, as well as the atypical microorganisms Mycoplasma pneumoniae, Chlamydia trachomatis, Chlamydophila pneumoniae, Legionella spp., Borrelia spp., Mycobacteria, Ureaplasma, and Toxoplasma. It is indicated in the management of atypical community acquired pneumonia, chlamydial infections, legionella pneumonia, and acute non-specific urethritis, as well as skin infections, disseminated mycobacterial infections, and the eradication of Helicobacter pylori as a component of triple therapy in peptic ulcer disease [1-3]. It has higher oral bioavailability and fewer gastrointestinal side effects than erythromycin [1,4].

Clarithromycin has poor aqueous and $\mathrm{pH}$-dependent solubility with dissolution rate-limited absorption corresponding to Biopharmaceutics Classification System (BCS) Class II [3,5-7]. The drug undergoes rapid degradation in strong acid to form decladinosyl clarithromycin and clarithromycin 9,12-hemiketal whose structures are shown in Figure $1[6,8]$.

Previous studies have reported that clarithromycin undergoes rapid degradation under conditions of low $\mathrm{pH}$ that exist in gastric fluid [6,9]. One such study reports $25 \%$ drug degradation at $\mathrm{pH} 2.0$ within 30 min of incubation, while incubation at $\mathrm{pH} 1.5$ yields $70 \%$ drug degradation within the same period [9]. Given that the gastric and intestinal residence times of clarithromycin are $0.5-2 \mathrm{~h}$ and 3-6 h, respectively, and since its systemic bioavailability is dependent on gastric stability and intestinal 
absorption [10], protection from acid degradation may play a key role in enhancing its bioavailability. Formulation approaches aimed at stabilization of clarithromycin under acidic conditions have included enteric coating, use of bioadhesive and mucoadhesive polymers, as well as amorphous solid dispersion matrices $[5,6,10]$. Clarithromycin is an essential antimicrobial agent, featured in the WHO model list of essential medicines for use in combination regimens for eradication of $H$. pylori in adults [11]. It is also a component of drug combinations used in the treatment of mycobacterium avium complex (MAC) in HIV-AIDS patients [12,13]. Quality problems associated with generic products of clarithromycin have been reported in the past, with a significant percentage of generic products failing to meet pharmacopoeial specifications for assay and dissolution, as well as failing the test for equivalence to innovator products [14-16].

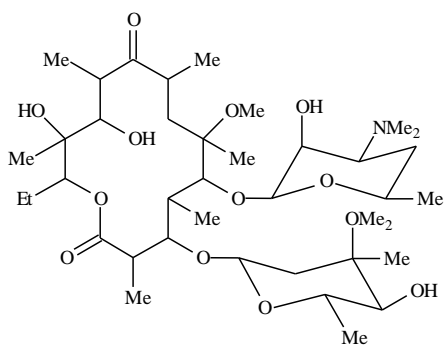

Clarithromycin

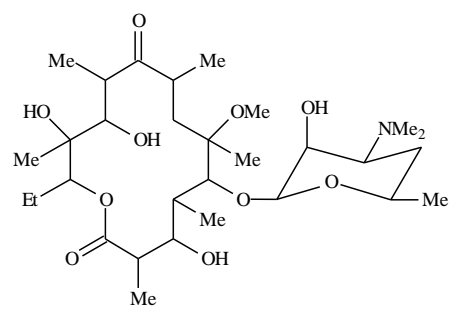

Decladinosyl clarithromycin

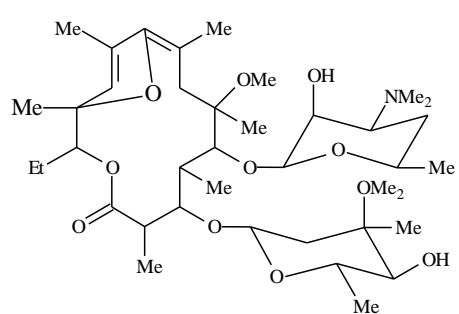

Clarithromycin-9,12-hemiketal

Figure 1. Chemical structures of clarithromycin and degradation products.

In Kenya, the Pharmacy and Poisons Board (PPB) is the regulatory body responsible for approvals, granting of market authorization of drugs as well as post market surveillance. Previous market surveillance endeavors by the PPB have focused on antimalarial, anti-tubercular, and antiretroviral drugs, leaving out other categories of medicines, notably antibiotics including clarithromycin. As at March 2014, there were about 49 brands of clarithromycin oral formulations registered by the PPB in Kenya [17]. There are no published reports of comparative dissolution or bioequivalence studies on these generic clarithromycin oral formulations in the Kenyan market. Given that clarithromycin belongs to BCS Class II, comparative dissolution studies are necessary to establish the pharmaceutical equivalence of generic formulations with the innovator products, $\mathrm{Klacid}^{\circledR}$ tablets, and suspension (Abbott Laboratories Ltd., Johannesburg, South Africa), which is an important pointer to their clinical efficacy.

The aim of this study was to evaluate the pharmaceutical equivalence of generic clarithromycin products in comparison with innovator products by Klacid ${ }^{\circledR}$ (Abbott Laboratories Ltd., Johannesburg, South Africa) through comparison of their dissolution profiles.

\section{Materials and Methods}

\subsection{Samples}

Clarithromycin samples were obtained from selected private retail pharmacy outlets within Nairobi County, Kenya. Clarithromycin suspensions $(125 \mathrm{mg} / 5 \mathrm{~mL})$ and clarithromycin $(500 \mathrm{mg})$ tablets/capsules were sampled for analysis. One batch each of the available products was obtained through purposive sampling over a period of three months. The innovator comparator products, Klacid ${ }^{\circledR}$ tablets and suspension (Abbott Laboratories Ltd., Johannesburg, South Africa), were similarly obtained. Additionally, one batch of Klaricid ${ }^{\circledR}$ tablets and one batch of suspension (Aesica Queenborough Ltd., Kent, UK) were obtained from Bordon Hampshire, England, for comparison purposes. 


\subsection{HPLC System}

Experiments were carried out using a Shimadzu Prominence high performance liquid chromatography (HPLC) system (Shimadzu Corp., Kyoto, Japan) comprising a CBM-20A Prominence communications bus module, an SPD-M20A Prominence UV/Visible photo diode array detector, an LC-20AD Prominence solvent delivery system, and an SIL-20AC Prominence auto sampler. The temperature was controlled using a CTO-20AC Prominence column oven with a block heating type thermostatic chamber, while the liquid chromatography (LC) system was controlled by LCSolutions Software Ver. 1.22, SP1. A Waters XTerra RP18, $5 \mu \mathrm{m}, 250 \times 4.6 \mathrm{~mm}$ ID chromatography column (Waters Corp., Wexford, Ireland) was used as the stationary phase.

\subsection{HPLC Method}

A published stability-indicating HPLC method for separation of clarithromycin and related substances was applied [8]. The method was verified before application for sample analysis. The optimum chromatographic conditions were established as a mobile phase consisting of acetonitrile, $0.2 \mathrm{M}$ phosphate buffer ( $\mathrm{pH} 6.8)$, and water $(40: 3.5: 56.5, v / v / v)$ delivered at a flow rate of $1.5 \mathrm{~mL} / \mathrm{min}$ through an XTerra RP $\mathrm{C}_{18}, 5 \mu \mathrm{m}\left(250 \times 4.6 \mathrm{~mm}\right.$ ID) column maintained at $56^{\circ} \mathrm{C}$ and UV detection at $205 \mathrm{~nm}$.

Clarithromycin working standard $(96.7 \% w / w)$ was used for determination of clarithromycin content in the assay and dissolution tests. Clarithromycin standard solutions were prepared using acetonitrile-mobile phase (40:60) to a concentration of $1 \mathrm{mg} / \mathrm{mL}$. Decladinosyl clarithromycin content was determined using relative retention time (RRT) reported in the literature [8] because the working standard was not available. During quantification of the decladinosyl clarithromycin content, normalization factors reported in the literature [8] were used.

\subsection{Assay}

\subsubsection{Tablets/Capsules}

Pooled powder from 20 tablets/capsules was weighed in triplicate whereof the samples were dissolved in acetonitrile with the aid of mechanical shaking for $45 \mathrm{~min}$ to a concentration of $2 \mathrm{mg} / \mathrm{mL}$. The stock solutions were diluted with mobile phase to a final concentration of $1 \mathrm{mg} / \mathrm{mL}$, filtered through $0.45 \mu \mathrm{m}$ filters, and subjected to HPLC analysis.

\subsubsection{Suspensions}

Clarithromycin granules for suspension were reconstituted using purified water according to label instructions. The contents of three bottles were mixed in a beaker and clarithromycin extracted sequentially using $0.067 \mathrm{M}$ dibasic potassium phosphate and methanol for $30 \mathrm{~min}$ each as prescribed in the United States Pharmacopeia (USP) [18]. Dilutions of the resulting solution were made using mobile phase to a concentration of $1 \mathrm{mg} / \mathrm{mL}$ and filtered through $0.45 \mu \mathrm{m}$ filters before HPLC analysis.

\subsection{Dissolution Profiles}

Samples were subjected to dissolution profile tests on a Labindia DS 8000 dissolution tester (Labindia Analytical Instruments Pvt. Ltd., Maharashtra, India) equipped with USP Apparatus 2, $900 \mathrm{~mL}$ of dissolution media, and a bowl temperature of $37^{\circ} \mathrm{C}$, and stirred at $50 \mathrm{rpm}$. The dissolution media used were $0.1 \mathrm{M} \mathrm{HCl}(\mathrm{pH} 1.2), 0.1 \mathrm{M}$ acetate buffer ( $\mathrm{pH} 4.5)$, and $0.2 \mathrm{M}$ phosphate buffer ( $\mathrm{pH}$ 6.8), all prepared as per USP specifications [18]. Six tablets/capsules and $6 \times 10 \mathrm{~mL}$ suspension aliquots were used for each dissolution profile. The sampling time points for tablets/capsules were 5, 10, 15, 30, 45 , and $60 \mathrm{~min}$, while those of suspensions were 10, 20, 30, 45, 60, and $90 \mathrm{~min}$.

Dissolution samples at $\mathrm{pH} 1.2$ were quenched with $0.2 \mathrm{M} \mathrm{NaOH}$ in order to stop further acidic degradation of clarithromycin. Suspension samples at $\mathrm{pH} 4.5$ and 6.8 were filtered using $0.45 \mu \mathrm{m}$ 
filters prior to HPLC analysis. Comparison of dissolution profiles was carried out by calculation of the similarity factor $\left(\mathrm{f}_{2}\right)$ using Equation (1) [19].

$$
f_{2}=50 \times \log \left\{\left[1+\left(\frac{1}{n}\right) \sum t=1^{n}\left(R_{t}-T_{t}\right)^{2}\right]^{-0.5} \times 100\right\}
$$

$n$-number of testing time points, $R_{t}$-average dissolution value of the reference product units at time $t$, and $T_{t}$-average dissolution value of the test product units at time $t$.

\section{Results and Discussion}

\subsection{Assay}

All tablet/capsule samples complied with USP assay specifications, while all the suspensions tested complied with USP limits for $\mathrm{pH}$ [18] and assay. For purposes of interpretation, the USP (2014) assay limits for clarithromycin tablets $(90.0 \%-110.0 \%)$ and suspensions $(90.0 \%-115.0 \%)$ were applied as acceptance criteria. The assay results obtained are shown in Table 1.

Table 1. Assay results of clarithromycin products analyzed $(n=9)$. Batch number omitted.

\begin{tabular}{cccc}
\hline Sample Code & Dosage Form & Registration Status in Kenya & Assay as \% Label Claim \\
\hline Reference $\left(\right.$ Klacid $\left.^{\circledR}\right)$ & Tablet & $\mathrm{R}$ & $105.9(0.97)$ \\
Reference $\left(\right.$ Klacid $\left.^{\circledR}\right)$ & Suspension & $\mathrm{R}$ & $109.6(1.85)$ \\
CL1 & Tablet & $\mathrm{R}$ & $100.9(0.87)$ \\
CL2 & Tablet & $\mathrm{R}$ & $100.2(1.40)$ \\
CL3 & Tablet & $\mathrm{R}$ & $100.1(0.56)$ \\
CL4 & Capsule & $\mathrm{R}$ & $102.1(0.33)$ \\
CL5 & Tablet & $\mathrm{R}$ & $99.2(0.39)$ \\
CL6 & Tablet & $\mathrm{R}$ & $99.3(1.61)$ \\
CL7 & Tablet & $\mathrm{R}$ & $98.7(0.38)$ \\
CL8 & Tablet & $\mathrm{R}$ & $101.5(1.44)$ \\
CL9 & Tablet & $\mathrm{R}$ & $102.0(1.13)$ \\
CL10 & Tablet & $\mathrm{R}$ & $98.8(0.53)$ \\
CL11 & Tablet & $\mathrm{R}$ & $98.4(0.39)$ \\
CL12 & Suspension & $\mathrm{R}$ & $107.8(1.16)$ \\
CL13 & Suspension & $\mathrm{R}$ & $108.8(0.88)$ \\
CL14 & Suspension & $\mathrm{NR}$ & $99.5(1.31)$ \\
CL15 & Tablet & $\mathrm{NR}$ & $103.5(0.27)$ \\
CL16 & Suspension & $110.1(0.84)$ \\
\hline
\end{tabular}

R-Registered; NR-Not Registered. Figures in parentheses represent the coefficient of variation ( $n=9$ replicate injections).

The assay values for generic tablets/capsules formulations (CL1-CL11) were $98.4 \%-102.1 \%$, while those of the innovator products Klaricid ${ }^{\circledR}$ (CL15) and $\mathrm{Klacid}^{\circledR}$ were $103.5 \%$ and $105.9 \%$ respectively. Suspension samples gave higher assay values $(99.5 \%-110.0 \%)$ than tablets, with the innovator products Klacid $^{\circledR}$ and Klaricid ${ }^{\circledR}$ (CL16) having the highest values at $109.6 \%$ and $110.1 \%$, respectively.

\subsection{Dissolution Profiles and Pharmaceutical Equivalence}

\subsection{1. $\mathrm{pH} 1.2$}

Dissolution of clarithromycin from tablets/capsules at $\mathrm{pH} 1.2$ proceeded with concomitant degradation to decladinosyl clarithromycin as the major product. A typical chromatogram of Klacid ${ }^{\circledR}$ tablets at $30 \mathrm{~min}$ (Figure 2) shows good resolution between the clarithromycin peak and that of the major degrade decladinosyl clarithromycin. 


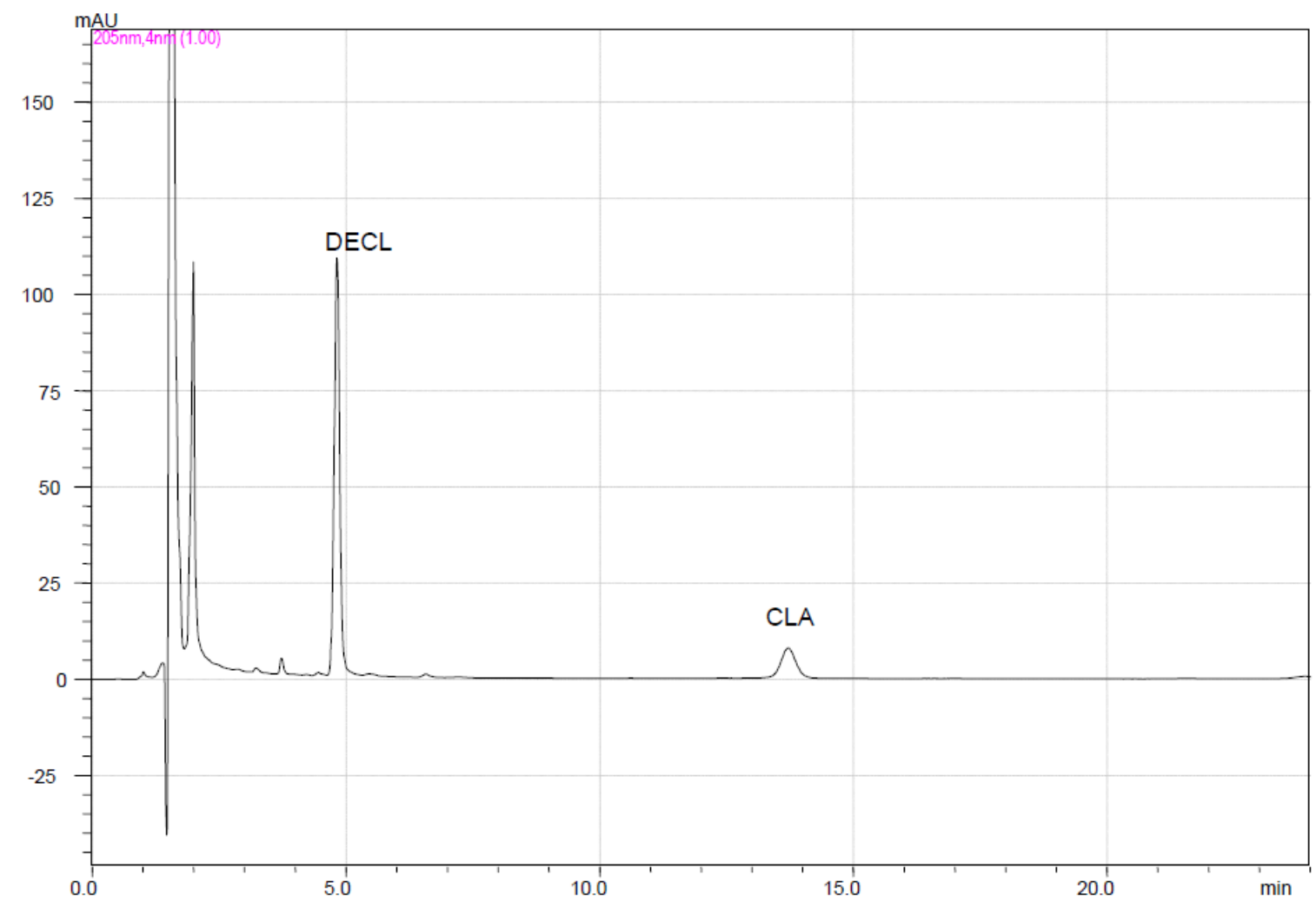

Figure 2. Typical chromatogram for clarithromycin dissolution ( $\mathrm{pH} 1.2)$ obtained at $30 \mathrm{~min}$. CLA—clarithromycin; DECL—decladinosyl clarithromycin. Chromatographic conditions: Column: XTerra ${ }^{\circledR} \mathrm{C}_{18} 5 \mu \mathrm{m}\left(250 \times 4.6 \mathrm{~mm}\right.$ ID); column temperature: $56^{\circ} \mathrm{C}$; mobile phase: acetonitrile-0.2 $\mathrm{M}$ phosphate buffer, $\mathrm{pH}$ 6.80-water (40:3.5:56.5\%, v/v/v); flow rate: $1.5 \mathrm{~mL} / \mathrm{min}$; detection: $205 \mathrm{~nm}$; concentration: $0.43 \mathrm{mg} / \mathrm{mL}$; injection volume: $100 \mu \mathrm{L}$.

The results for dissolution and degradation profiles for all samples tested at this $\mathrm{pH}$ are displayed in Table 2. In the table, the sum of clarithromycin and decladinosyl clarithromycin has been expressed as total clarithromycins. For this purpose, the areas of decladinosyl clarithromycin were corrected using normalization factors reported in the literature [8]. The similarity factors $\left(f_{2}\right)$ for each sample with respect to the innovator product $\mathrm{Klacid}^{\circledR}$ tablets are also displayed in the table. Compliance for equivalence was set at $\left(\mathrm{f}_{2}\right) \geq 50$ [19].

At this $\mathrm{pH}$, low dissolution percentages were observed at early time points for some samples, leading to high variability and consequently a high percentage coefficient of variation values $(\mathrm{CV}, \%)$. Out of the 13 tablet/capsule samples tested, five (CL1, CL3, CL10, CL11 and CL15) had CV, \% $<20$ at 5, 10, and $15 \mathrm{~min}$ and CV, \% <10 at 30, 45, and $60 \mathrm{~min}$. Three samples (CL5, CL6 and CL8) had marginally raised $\mathrm{CV}, \%$ values at a 5 -min sampling time, $\mathrm{CV}, \%<20$ at 10 and $15 \mathrm{~min}$, while $\mathrm{CV}, \%$ at 30,45 and 60 min ranged between 12.6 and 5.9. Notably, one capsule sample (CL4) had erratic dissolution with drug release occurring at once upon rapture of individual capsules, thus giving rise to $\mathrm{CV}, \%>20$ at all time points.

Six tablet and capsule samples (CL1, CL4, CL6, CL8, CL11, and CL15) were found to be pharmaceutically equivalent to $\mathrm{Klacid}^{\circledR}$, translating to a 50\% success rate. Samples CL2, CL5, and CL10 were non-equivalent to $\mathrm{Klacid}^{\circledR}$ on account of higher percentage total clarithromycins dissolved, while samples CL3, CL7, and CL9 were non-equivalent due to lower dissolution rates. Graphical presentations of the dissolution and degradation profiles for some non-equivalent samples are displayed in Figure 3 alongside that of $\mathrm{Klacid}^{\circledR}$ tablets for comparison. 
Table 2. Dissolution and degradation profiles of clarithromycin tablets/capsules at pH 1.2.

\begin{tabular}{|c|c|c|c|c|c|c|c|c|c|c|c|c|c|c|}
\hline \multirow{2}{*}{ Dissolution Time (min) } & \multicolumn{14}{|c|}{ Average $\%$ Drug Released $(n=6)$} \\
\hline & & Ref. (Klacid $\left.{ }^{\circledR}\right)$ & CL1 & CL2 & CL3 & CL4 & CL5 & CL6 & CL7 & CL8 & CL9 & CL10 & CL11 & CL15 \\
\hline \multirow{3}{*}{5} & CLA & 8.97 & 8.41 & 14.08 & 1.43 & 5.16 & 37.64 & 2.29 & 2.61 & 3.77 & 0.88 & 53.90 & 5.39 & 11.70 \\
\hline & DECL & 2.39 & 3.78 & 5.24 & 0.83 & 1.48 & 13.23 & 1.38 & 1.17 & 1.20 & 2.01 & 10.02 & 5.51 & 2.17 \\
\hline & TOTAL CLA & 11.36 & 12.19 & 19.32 & 2.26 & 6.64 & 50.87 & 3.67 & 3.78 & 4.97 & 2.88 & 63.92 & 10.90 & 13.87 \\
\hline \multirow{3}{*}{10} & CLA & 12.20 & 8.59 & 18.32 & 2.58 & 11.45 & 27.06 & 4.02 & 3.51 & 6.90 & 2.77 & 40.21 & 7.09 & 14.47 \\
\hline & DECL & 6.48 & 8.94 & 11.43 & 1.16 & 5.37 & 25.42 & 3.60 & 1.63 & 4.60 & 5.03 & 30.46 & 5.00 & 4.18 \\
\hline & TOTAL CLA & 18.67 & 17.53 & 29.75 & 3.74 & 16.82 & 52.48 & 7.62 & 5.14 & 11.50 & 7.80 & 70.67 & 12.09 & 18.65 \\
\hline \multirow{3}{*}{15} & CLA & 11.89 & 7.58 & 23.16 & 4.25 & 11.88 & 18.48 & 5.60 & 3.78 & 7.96 & 2.43 & 20.99 & 7.93 & 17.33 \\
\hline & DECL & 11.53 & 13.56 & 20.45 & 2.56 & 11.80 & 33.79 & 7.03 & 2.93 & 8.96 & 8.95 & 40.03 & 8.79 & 8.91 \\
\hline & TOTAL CLA & 23.42 & 21.14 & 44.06 & 6.81 & 23.68 & 52.27 & 12.63 & 6.71 & 16.92 & 11.38 & 61.02 & 16.72 & 26.24 \\
\hline \multirow{3}{*}{30} & CLA & 8.61 & 5.15 & 6.77 & 5.28 & 7.02 & 5.80 & 5.87 & 2.69 & 5.76 & 3.53 & 3.26 & 6.79 & 9.76 \\
\hline & DECL & 24.50 & 25.17 & 38.53 & 8.97 & 23.00 & 46.82 & 18.24 & 10.57 & 20.25 & 18.78 & 51.48 & 20.06 & 20.77 \\
\hline & TOTAL CLA & 33.12 & 30.32 & 45.31 & 14.25 & 30.02 & 52.62 & 24.12 & 13.26 & 26.01 & 22.31 & 54.74 & 26.85 & 30.53 \\
\hline \multirow{3}{*}{45} & CLA & 6.10 & 3.83 & 1.81 & 5.45 & 2.99 & 2.14 & 5.37 & 3.16 & 3.84 & 2.11 & 0.48 & 5.67 & 6.04 \\
\hline & DECL & 34.12 & 32.98 & 44.75 & 15.85 & 35.90 & 49.81 & 27.43 & 18.17 & 28.49 & 21.86 & 53.17 & 28.76 & 30.26 \\
\hline & TOTAL CLA & 40.22 & 36.81 & 46.56 & 21.30 & 38.90 & 51.95 & 32.80 & 21.33 & 32.33 & 23.97 & 53.65 & 34.43 & 36.30 \\
\hline \multirow{3}{*}{60} & CLA & 5.59 & 2.99 & 0.72 & 5.52 & 2.91 & 1.07 & 4.23 & 2.59 & 2.72 & 2.00 & 0.03 & 4.37 & 3.43 \\
\hline & DECL & 40.44 & 38.21 & 43.39 & 23.04 & 33.90 & 49.35 & 40.40 & 18.20 & 35.44 & 25.45 & 54.10 & 36.56 & 35.27 \\
\hline & TOTAL CLA & 46.04 & 41.20 & 44.11 & 28.55 & 36.81 & 50.42 & 44.63 & 20.79 & 38.16 & 27.45 & 54.13 & 40.93 & 38.70 \\
\hline \multicolumn{2}{|c|}{ Similarity factor $\left(f_{2}\right)$} & 100 & 80.4 & 46.0 & 40.2 & 69.2 & 28.8 & 54.6 & 37.9 & 58.9 & 44.8 & 22.2 & 64.7 & 72.2 \\
\hline
\end{tabular}

n-number of replicates; Ref.-reference product; CL1-CL15—sample codes; CLA—clarithromycin; DECL—decladinosyl clarithromycin; TOTAL CLA—total clarithromycin. 
Klacid $^{\circledR}$ released 33\% total clarithromycins within 30 min whereby the major component was decladinosyl clarithromycin (24\%). Three generic products released over $45 \%$ total clarithromycins within $30 \mathrm{~min}$. Samples CL5 and CL10 released 52\% and 70\% total clarithromycins, respectively, in the first $10 \mathrm{~min}$ while CL2 released $45 \%$ in $30 \mathrm{~min}$. In both CL5 and CL10, clarithromycin degradation proceeded fast, producing 45\%-50\% decladinosyl clarithromycin within $30 \mathrm{~min}$. Samples CL3, CL7, and CL9 had remarkably low dissolution values ranging 20\%-29\%, indicating significant formulation differences between them and the innovator product.

In all the four suspensions tested, no clarithromycin peak was detected, indicating that there was no drug release under this $\mathrm{pH}$.

\section{Dissolution and degradation profile for Klacid ${ }^{\text {(2) }}$ tablets at $\mathrm{pH} 1.2$}

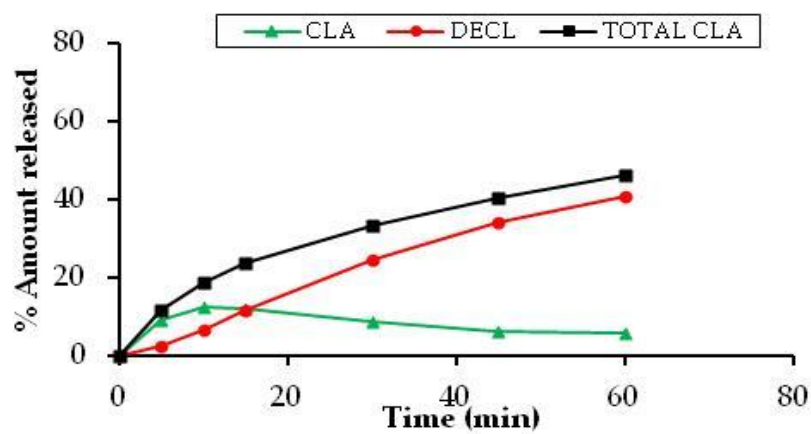

Dissolution and degradation profile for sample

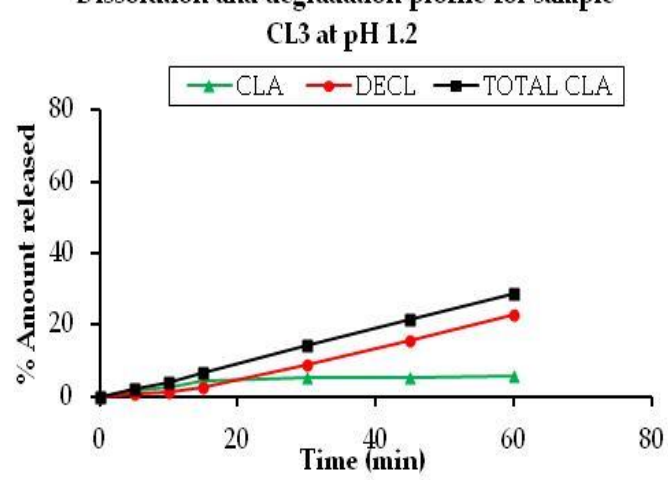

Dissolution and degradation profile for sample CL7 at $\mathrm{pH} 1.2$

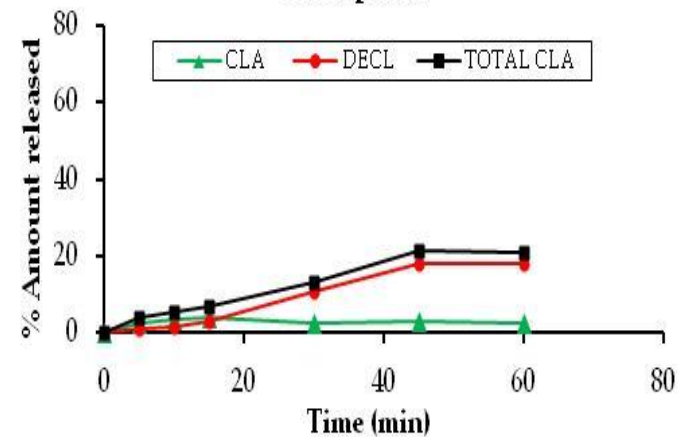

Dissolution and degradation profile for sample

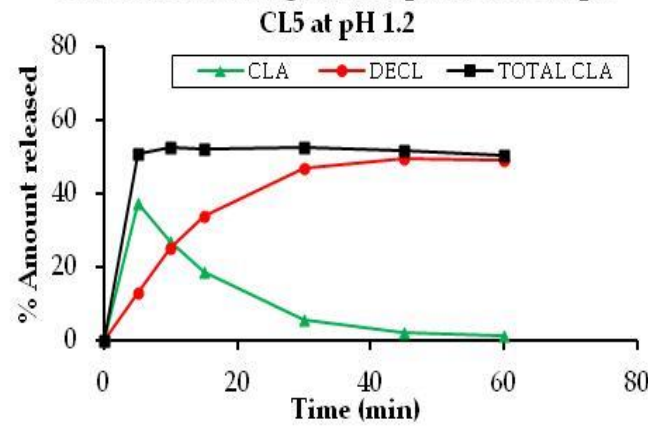

Dissolution and degradation profile for sample CL10 at $\mathrm{pH} 1.2$

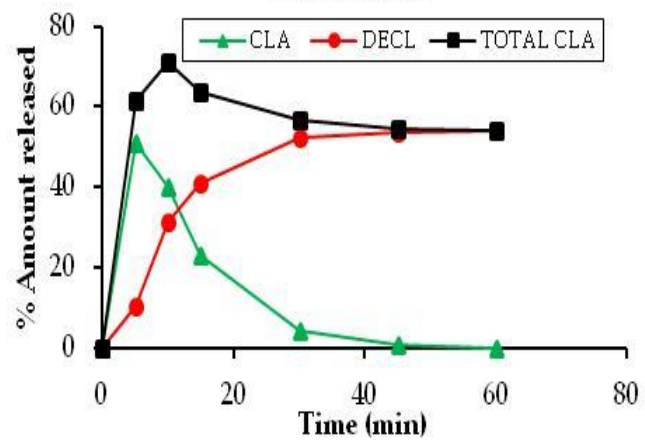

Figure 3. Dissolution and degradation profiles of Klacid $^{\circledR}$ tablets and samples CL3, CL5, CL7, and CL10 at $\mathrm{pH} 1.2$. 


\subsection{2. $\mathrm{pH} 4.5$}

The average percentage dissolution of tablet/capsule samples at $\mathrm{pH} 4.5$ were computed from peak areas, tabulated (Table 3), and plotted as a function of dissolution time (Figure 4). The similarity factors are as shown in Table 3.

Table 3. Comparative dissolution profiles and $\mathrm{f}_{2}$ values for clarithromycin tablets/capsules at $\mathrm{pH} 4.5$.

\begin{tabular}{cccccccc}
\hline Time (min) & $\mathbf{5}$ & $\mathbf{1 0}$ & $\mathbf{1 5}$ & $\mathbf{3 0}$ & $\mathbf{4 5}$ & $\mathbf{6 0}$ & $\mathbf{f}_{\mathbf{2}}$ \\
\hline Sample Code & \multicolumn{7}{c}{ \% } \\
\hline Refarithromycin Dissolved \\
\hline Rlacid $^{\circledR}$ ) & 88.82 & 91.60 & 92.92 & 93.12 & 93.31 & 93.68 & $\mathbf{1 0 0}$ \\
CL1 & 86.91 & 91.23 & 92.54 & 93.20 & 93.81 & 94.48 & $\mathbf{9 3 . 6}$ \\
CL2 & 34.56 & 63.32 & 88.80 & 93.10 & 94.78 & 94.87 & $\mathbf{3 0 . 0}$ \\
CL3 & 77.06 & 82.74 & 84.27 & 86.46 & 86.86 & 87.24 & $\mathbf{5 3 . 7}$ \\
CL4 & 2.93 & 30.43 & 58.14 & 80.76 & 83.44 & 85.34 & $\mathbf{1 6 . 9}$ \\
CL5 & 75.45 & 94.19 & 94.86 & 95.25 & 95.37 & 95.64 & $\mathbf{6 1 . 5}$ \\
CL6 & 67.53 & 93.94 & 94.61 & 94.99 & 95.39 & 95.77 & $\mathbf{5 2 . 4}$ \\
CL7 & 23.40 & 57.86 & 73.47 & 88.46 & 96.52 & 97.75 & $\mathbf{2 5 . 3}$ \\
CL8 & 90.62 & 95.85 & 96.88 & 97.27 & 97.40 & 98.44 & $\mathbf{6 9 . 5}$ \\
CL9 & 46.87 & 65.30 & 82.15 & 91.31 & 91.79 & 91.42 & $\mathbf{3 4 . 2}$ \\
CL10 & 73.71 & 85.81 & 87.73 & 89.57 & 90.59 & 90.16 & $\mathbf{5 6 . 6}$ \\
CL11 & 90.57 & 90.67 & 90.64 & 90.66 & 90.88 & 90.91 & $\mathbf{8 0 . 9}$ \\
CL15 & 93.65 & 94.87 & 95.17 & 95.22 & 95.56 & 95.78 & $\mathbf{7 5 . 2}$ \\
\hline
\end{tabular}

All tablet/capsule samples released $>80 \%$ of the drug within 30 min of dissolution. The highest release rate was 97\% (CL8), while the lowest was 81\% (CL4). No clarithromycin degradation was noted at this $\mathrm{pH}$. Drug release for all suspensions at $\mathrm{pH} 4.5$ was $<2 \%$ within 90 min, probably due to enteric coating.

Samples CL2, CL4, CL7, and CL9 were found to be pharmaceutically non-equivalent to Klacid ${ }^{\circledR}$. Non-equivalence in all these samples arose due to slow release rates at the early sampling points. The dissolution results indicate variability of product design, thus giving rise to differences in drug release characteristics despite the assay values being comparable to that of the innovator product.

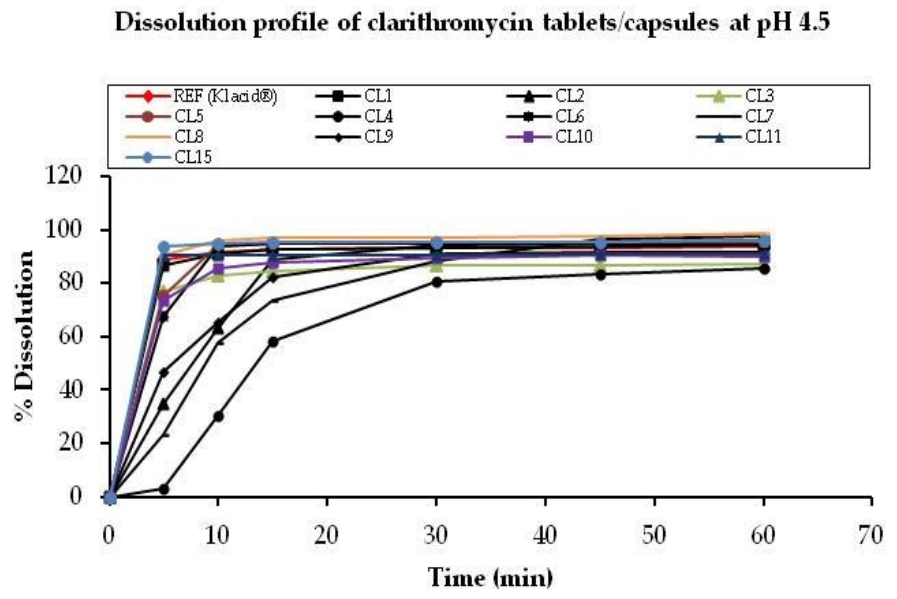

Figure 4. Comparative dissolution profile curves for clarithromycin tablets/capsules at $\mathrm{pH}$ 4.5. The CV, $\%$ values at this $\mathrm{pH}$ for 8 out of 13 samples tested (Klacid ${ }^{\circledR}, \mathrm{CL1}, \mathrm{CL} 3, \mathrm{CL} 5, \mathrm{CL} 8, \mathrm{CL10}, \mathrm{CL11}$, and CL15) were $<20$ at 5, 10, and 15 min sampling time and $<10$ at 30, 45, and $60 \mathrm{~min}$. Sample CL6 had a CV, \% of 20.9 at $5 \mathrm{~min}$ and $<10$ at the rest of sampling time points. Samples CL2, CL7, and CL9 had CV, \% >20 at 5 and $10 \mathrm{~min}$ while the $\mathrm{CV}, \%$ was $<20$ at $15 \mathrm{~min}$ and $<10$ at 30, 45 and $60 \mathrm{~min}$. The capsule sample, CL4, yielded erratic dissolution with drug release occurring at once upon rapture of individual capsules, leading to $\mathrm{CV}, \%>20$ at the early sampling time points. 


\subsection{3. $\mathrm{pH} 6.8$}

Enhanced dissolution was noted for all samples at $\mathrm{pH} 6.8$ compared to $\mathrm{pH} 1.2$ and $\mathrm{pH} 4.5$. The percentage drug released at each time point as well as the similarity factors are recorded in Table 4 for tablets/capsules while those for suspensions are shown in Table 5. Comparative dissolution plots for tablet/capsule samples are as shown in Figure 5.

Table 4. Comparative dissolution profiles and $\mathrm{f}_{2}$ factors for clarithromycin tablets and capsules at $\mathrm{pH} 6.8$.

\begin{tabular}{cccccccc}
\hline Time (min) & $\mathbf{5}$ & $\mathbf{1 0}$ & $\mathbf{1 5}$ & $\mathbf{3 0}$ & $\mathbf{4 5}$ & $\mathbf{6 0}$ & $\mathbf{f}_{\mathbf{2}}$ \\
\hline Sample Code & \multicolumn{7}{c}{ \% Clarithromycin Dissolved } \\
\hline Ref (Klacid $\left.^{\circledR}\right)$ & 29.02 & 46.97 & 56.71 & 66.41 & 71.87 & 74.02 & $\mathbf{1 0 0}$ \\
CL1 & 30.34 & 40.55 & 45.64 & 54.16 & 57.86 & 60.14 & $\mathbf{5 4 . 8}$ \\
CL2 & 26.43 & 42.11 & 49.13 & 57.82 & 62.02 & 64.75 & $\mathbf{5 5 . 8}$ \\
CL3 & 16.99 & 27.18 & 34.56 & 45.51 & 51.30 & 54.19 & $\mathbf{3 5 . 5}$ \\
CL4 & 0.04 & 3.39 & 19.16 & 44.35 & 53.73 & 58.36 & $\mathbf{2 6 . 5}$ \\
CL5 & 18.19 & 27.02 & 32.74 & 42.57 & 48.25 & 50.03 & $\mathbf{3 3 . 3}$ \\
CL6 & 29.50 & 44.49 & 51.00 & 60.70 & 65.19 & 67.89 & $\mathbf{6 4 . 4}$ \\
CL7 & 6.35 & 16.22 & 23.58 & 37.02 & 44.92 & 50.22 & $\mathbf{2 7 . 6}$ \\
CL8 & 22.32 & 34.95 & 42.07 & 53.53 & 58.23 & 61.50 & $\mathbf{4 5 . 4}$ \\
CL9 & 11.47 & 23.80 & 33.44 & 46.96 & 52.65 & 56.17 & $\mathbf{3 4 . 7}$ \\
CL10 & 34.18 & 47.53 & 56.96 & 68.28 & 71.99 & 72.43 & $\mathbf{7 9 . 7}$ \\
CL11 & 40.94 & 52.83 & 58.27 & 66.66 & 69.44 & 70.66 & $\mathbf{6 1 . 8}$ \\
CL15 & 34.44 & 46.21 & 51.73 & 58.53 & 60.87 & 62.75 & $\mathbf{5 5 . 2}$ \\
\hline
\end{tabular}

Table 5. Dissolution profiles and $\mathrm{f}_{2}$ factors for clarithromycin suspensions at $\mathrm{pH} 6.8$.

\begin{tabular}{cccccc}
\hline \multirow{2}{*}{ Time (min) } & \multicolumn{5}{c}{ Percentage Drug Dissolved } \\
\cline { 2 - 6 } & Ref (Klacid $^{\circledR}$ ) & CL12 & CL13 & CL14 & CL16 \\
\hline 0 & 0 & 0.22 & 0.68 & 0 & 0.08 \\
10 & 11.38 & 14.05 & 0.57 & 2.14 & 11.69 \\
20 & 36.08 & 41.85 & 0.81 & 1.21 & 24.83 \\
30 & 63.35 & 51.7 & 2.25 & 1.27 & 55.5 \\
45 & 65.40 & 67.09 & 5.21 & 2.84 & 75.58 \\
60 & 68.64 & 83.99 & 14.90 & 8.04 & 82.39 \\
90 & 66.94 & 95.35 & 14.90 & 21.60 & 94.81 \\
\hline Similarity factor ${\left(\mathbf{f}_{\mathbf{2}}\right)}$ & $\mathbf{1 0 0}$ & $\mathbf{4 2 . 4}$ & $\mathbf{1 4 . 3}$ & $\mathbf{1 5 . 2}$ & $\mathbf{4 2 . 0}$ \\
\hline
\end{tabular}

Dissolution profiles of clarithromycin tablets/capsules at $\mathrm{pH} 6.8$

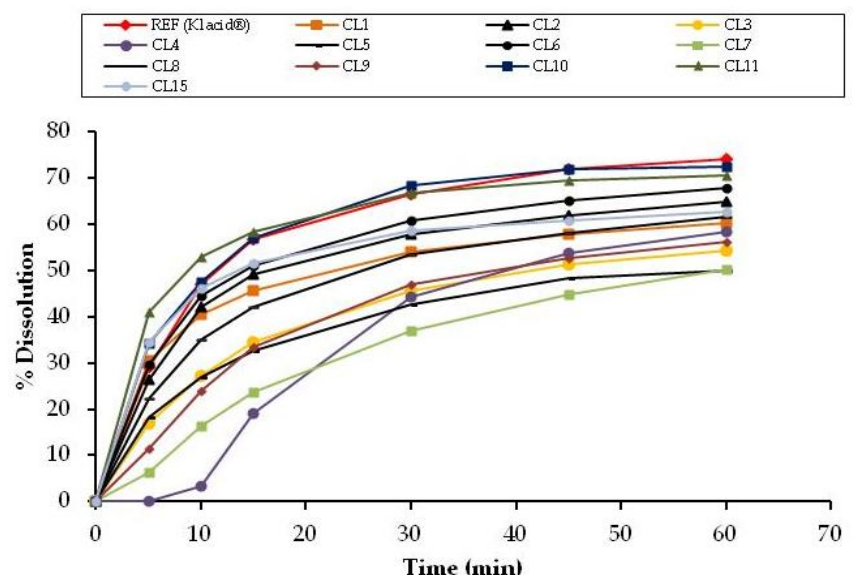

Figure 5. Comparative dissolution profiles of clarithromycin tablets/capsules at pH 6.8. 
The CV, \% values for nine out of the thirteen samples tested (CL1, CL2, CL3, CL6, CL7, CL8, CL10, CL11 and CL15) were $<20$ at 5, 10, 15 min and $<10$ at 30, 45 and 60 min. Klacid ${ }^{\circledR}$ and CL9 had CV, $\%>20$ at the two first sampling points and $<10$ at all other time points, while CL5 had CV, $\%<20$ at 5 , 10 , and $15 \mathrm{~min}$ and a CV, \% of 11.3-12.3 at 30, 45, and $60 \mathrm{~min}$. The capsule sample, CL4, had CV, \% >20 at the three early time points due to erratic drug release from individual capsule units.

Out of the 12 tablet/capsule products tested, 6 met the requirements for similarity factor $\left(\mathrm{f}_{2}\right)$. Samples CL3, CL4, CL5, CL7, CL8, and CL9 were found to be non-equivalent to Klacid ${ }^{\circledR}$ due to lower dissolution rates.

None of the four suspensions tested met the requirement for similarity factor $\left(\mathrm{f}_{2}\right)$ relative to the innovator comparator product, Klacid ${ }^{\circledR}$. The reference sample $\left(\mathrm{Klacid}^{\circledR}\right)$ and Sample CL16, being the innovator products by the same manufacturer, are expected to be equivalent. Their non-equivalence noted in the experiments carried out raises concerns about standardization of manufacturing sites as per the scale-up and post-approval changes (SUPAC) guidelines prescribed by the Centre for Drug Evaluation and Research (CDER) of the United States Food and Drug Administration (US FDA) [20]. Notably, Samples CL13 and CL14 yielded minimal drug release over the dissolution period, which raises valid concerns about their efficacy.

\subsection{Comparative Evaluation for Similarity Factors}

A summary of $f_{2}$ data for all analyzed samples is graphically illustrated in Figure 6. Overall, significant differences were observed in the dissolution profiles of the clarithromycin products tested. While all products complied with assay specifications, the majority of generic products did not comply with the specifications for similarity factor $\left(\mathrm{f}_{2}\right)$ with the innovator products under the three-dissolution media used. Only 4 ( $25 \%$ ) out of the 16 products tested met the acceptance criteria for similarity factor, $\left(f_{2}\right)$ relative to Klacid ${ }^{\circledR}$ tablets and suspension. Notably, Samples CL7 and CL9 consistently failed to meet the $f_{2}$ acceptance criteria at all three $\mathrm{pH}$ values. The results obtained indicate that the majority of clarithromycin generic products in the Kenyan market may not be pharmaceutically equivalent to the innovator products. Such products are deemed unacceptable according to the US FDA guidelines, which also recommend that further guidance be sought from the CDER to determine whether an in vivo study is appropriate for products with an $\mathrm{f}_{2}<50$ [21].

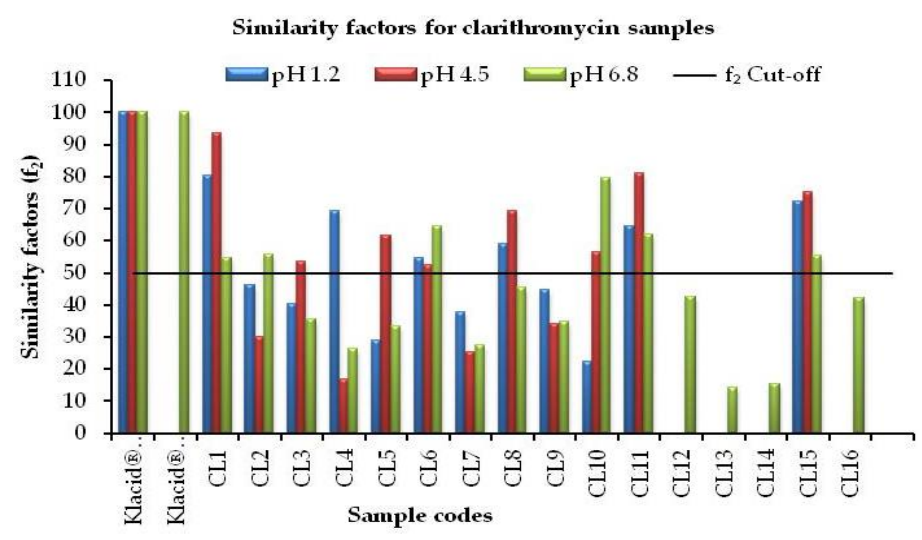

Figure 6. Graphical presentation of similarity factors for all clarithromycin samples tested at $\mathrm{pH}$ 1.2, 4.5 , and 6.8 .

\section{Conclusions}

In this study, it was noted that a significant percentage of clarithromycin generics did not comply with the specifications of similarity factor with respect to innovator products despite yielding comparable single-point dissolution results. At $\mathrm{pH}$ 1.2, sample CL2 yielded comparable results to the reference sample at $60 \mathrm{~min}$ run time, but failed to meet the specification for similarity factor. At $\mathrm{pH} 4.5$, 
all 12 samples tested released $\geq 80 \%$ of the drug at a 30 min dissolution run time, which is comparable to pharmacopoeial specifications for a single point dissolution test, but four of these (CL2, CL4, CL7, and CL9) failed to meet the specifications for similarity factor with respect to the reference sample. Notably, Samples CL2 and CL9 had comparable results to the reference sample at 30, 45 and 60 min run time, while CL7 yielded comparable results at 45 and 60 min run time. The study findings may therefore point to the necessity of applying dissolution profile comparison with several dissolution time-points (five or six) as a measure of in vitro pharmaceutical equivalence between generic and innovator products, as single-point dissolution studies may not be sufficiently discriminative for the same.

The results obtained in this study will serve to inform regulatory authorities on the quality of clarithromycin products in the Kenyan market with respect to the pharmaceutical equivalence of generics to the innovator products. The findings indicate the need for extensive studies to establish pharmaceutical equivalence of generic products in the market for interchangeability.

Acknowledgments: This study was made possible by a scholarship granted by the University of Nairobi through the Department of Pharmaceutical Chemistry. We thank the National Quality Control Laboratory, Kenya where the research work was carried out. We acknowledge C. Rotich, H. Mugo, J. Kalama, D. Moenga, J. Nguyo, and O. King'ondu for technical input.

Author Contributions: R.O.M. and K.O.A. conceived and designed the experiments; R.O.M. performed the experiments and analyzed the data; H.K.C. provided analysis equipment and reagents; K.O.A. and H.K.C. supervised experimental work; R.O.M. and K.O.A. prepared the manuscript.

Conflicts of Interest: The authors declare no conflict of interest.

Declaration: This research was part of R.O.M.'s Master of Pharmacy thesis project (2014). The full thesis has been deposited in the University of Nairobi's e-repository as per the University's open access policy and is available at erepository.uonbi.ac.ke, while the PowerPoint presentation of the same is available at pharm-school.uonbi.ac.ke.

\section{References}

1. Zuckerman, J. Macrolides and ketolides: Azithromycin, clarithromycin, telithromycin. Infect. Dis. Clin. N. Am. 2004, 18, 621-649. [CrossRef] [PubMed]

2. Castrellon, P.G.; Buitron, J.L.; Canto, V.B.; Santibanez, G.S.; Ranero, A. Efficacy and safety of clarithromycin in paediatric patients with upper respiratory infections: A systematic review with meta-analysis. Rev. Investig. Clin. 2012, 64, 126-135.

3. Sutar, R.; Masareddy, R.; Nagesh, C.; Joshi, V.; Attimarad, S. Formulation and evaluation of clarithromycin poorly soluble drug as microemulsion. Int. Res. J. Pharm. 2011, 2, 153-158.

4. Lemke, T.L.; Williams, D.A.; Roche, V.F.; Zito, S.W. Foye's Principles of Medicinal Chemistry, 7th ed.; Williams: Baltimore, MD, USA, 2012.

5. Lakum, S.; Patel, Y.; Thoriya, J. Formulation and Evaluation of Bioadhesive Gastroretentive Drug Delivery System of Clarithromycin. Inventi Impact. 2013. Available online: http://inventi.in/journal/article/impact/ 2/5437/ndds/pi (accessed on 16 April 2017).

6. Pereira, J.M.; Mejia-Ariza, R.; Ilevbare, G.; McGettigan, E.; Sriranganathan, N.; Taylor, L.; Davis, R.; Edgar, K. Interplay of degradation, dissolution and stabilization of clarithromycin and its amorphous solid dispersions. Mol. Pharm. 2013, 10, 4640-4653. [CrossRef] [PubMed]

7. Zhang, X.; Chen, X.; Hu, L.; Tang, X.; Li, S.; Zhong, D. Evaluation of in vitro dissolution and in vivo absorption for two different film-coated pellets of clarithromycin. Arch. Pharm. Res. 2005, 28, 977-982. [CrossRef] [PubMed]

8. Abuga, K.; Chepkwony, H.; Roets, E.; Hoogmartens, J. A stability-indicating HPLC method for the separation of clarithromycin and related substances in bulk samples. J. Sep. Sci. 2001, 24, 849-855. [CrossRef]

9. Fujiki, S.; Iwao, Y.; Kobayashi, M.; Miyagishima, A.; Itai, S. Stabilization mechanism of clarithromycin tablets under gastric $\mathrm{pH}$ conditions. Chem. Pharm. Bull. 2011, 59, 553-558. [CrossRef] [PubMed]

10. Chandira, M.; Sachin; Venkateshwarlu, B.; Bhowmik, D.; Jayakar, B. Formulation and evaluation of controlled release mucoadhesive oral tablet of clarithromycin. Der Pharm. Lett. 2009, 1, 83-91. 
11. World Health Organization. WHO Model List of Essential Medicines, 18th list. Available online: http://www.who.int/medicines/publications/essentialmedicines/18th_EML_Final_web_8Jul13.pdf (accessed on 4 November 2013).

12. Shahbaziniaz, M.; Foroutan, M.; Bolourchian, N. Dissolution rate enhancement of clarithromycin using ternary ground mixtures: Nanocrystal formation. Iran. J. Pharm. Res. 2013, 12, 587-598. [PubMed]

13. Kanizaj, T.; Katicic, M.; Skurla, B.; Ticak, M.; Plecko, V.; Kalenic, S. H. pylori eradication therapy success regarding different treatment periods based on clarithromycin or metronidazole triple-therapy regimens. Helicobacter 2009, 14, 29-35. [CrossRef] [PubMed]

14. Nightingale, C.H. A Survey of the quality of generic clarithromycin products manufactured in Slovenia and Israel. Adv. Ther. 2000, 17, 167-178. [CrossRef] [PubMed]

15. Nightingale, C.H. A Survey of the quality of generic clarithromycin products from 13 countries. Clin. Drug Investig. 2000, 19, 293-305. [CrossRef]

16. Nightingale, C.H. A Survey on the quality of generic clarithromycin products from 18 countries. Clin. Drug Investig. 2005, 25, 135-152. [CrossRef] [PubMed]

17. Pharmacy and Poisons Kenya. Registered Human Drugs. Available online: http://www. pharmacyboardkenya.org (accessed on 23 March 2014).

18. USP. United States Pharmacopeia; United States Pharmacopeial Convention: Rockville, MD, USA, 2014.

19. US FDA. Guidance for Industry: Dissolution Testing of Immediate Release Solid Oral Dosage Forms. Available online: http://www.fda.gov/downloads/drugs/guidancecomplianceregulatoryinformation/ guidances/ucm070237.pdf (accessed on 5 November 2013).

20. CDER. Guidance for Industry: Immediate Release Solid Oral Dosage Forms. Scale-Up and Post-Approval Changes: Chemistry, Manufacturing and Controls, In Vitro Dissolution Testing and In Vivo Bioequivalence Documentation. Available online: https://www.fda.gov/downloads/drugs/ guidancecomplianceregulatoryinformation/guidances/ucm070636.pdf (accessed on 4 September 2014).

21. US FDA. Guidance for Industry: Bioavailability and Bioequivalence Studies for Orally Administered Drug Products—general considerations. Available online: http://www.fda.gov/ohrms/dockets/ac/03/briefing/ 3995B1_07_GFI-BioAvail-BioEquiv.pdf (accessed on 13 January 2014).

(C) 2017 by the authors. Licensee MDPI, Basel, Switzerland. This article is an open access article distributed under the terms and conditions of the Creative Commons Attribution (CC BY) license (http:/ / creativecommons.org/licenses/by/4.0/). 